\title{
Culturally Sustaining Pedagogy Through Arts-Based Learning: Preservice Teachers Engage Emergent Bilinguals
}

\author{
Nancy Pauly, Karla V. Kingsley, and Asha Baker
}

\begin{abstract}
Rooted in arts-based learning, funds of knowledge, and culturally sustaining pedagogies, this paper describes the experiences of a cohort of preservice teachers who co-created arts integration units with emergent bilingual students, engaging them in the creation of plays based on culturally relevant children's literature. This cohort was designed by eight professors to prepare professionals to serve the needs of culturally diverse and economically vulnerable communities through arts-based teaching and assessment modalities. We share three telling cases about these preservice teachers' reflections on their pedagogy and their students' engagement illustrating how the arts can foster inclusive ways of knowing and communicating.
\end{abstract}

\section{Background}

Studies have demonstrated that participation in the arts contributes to academic and social success for diverse learners, especially those living in poverty (Catterall, Dumais, \& Hampden-Thompson, 2012), English learners (Craig \& Paraiso, 2008), and students with disabilities (Mason, Steedly, \& Thormann, 2008). In this paper we share the experiences of 13 preservice teachers who used arts-based learning approaches (Stewart \& Walker, 2005) throughout their three-semester student teaching courses and fieldwork while drawing from their students' funds of knowledge (González, Moll, \& Amanti, 2009) to develop culturally sustaining pedagogies (Paris \& Alim, 2017). The preservice teachers (PSTs) were undergraduate students in a cohort named the Teacher Education Collaborative in Language Diversity and Arts Integration (TECLA).

The TECLA model was developed in 2014 by an interdisciplinary group of eight university faculty with the goal of addressing the educational needs of diverse learners, particularly emergent bilingual youth and those living in economically vulnerable communities. TECLA was created to improve preservice and in-service teacher quality by preparing teachers for careers in culturally diverse and economically vulnerable communities, and explore arts-based teaching, learning, and assessment to support diverse ways of knowing and communicating.

This study was conducted in a dual language elementary school in the international district of a large city in the southwestern United States. Students at the school are from diverse backgrounds with varying levels of ability and readiness for school. Many are English learners from immigrant or refugee families, and all students are eligible for free or reduced-price meals. 
The research question guiding this investigation was: how are preservice teachers' understandings of their elementary students' literacies, learning, and funds of knowledge mediated through arts-based learning when transforming a book into a play? Using qualitative methods, the authors examined coursework and interview data from preservice teachers including reflections, observations, and interpretations of elementary students' learning during an interdisciplinary arts-based unit. The instructional objectives were to build a culturally sustaining curriculum based on multicultural children's literature by selecting a book, planning an interdisciplinary unit based on students' funds of knowledge, teaching that unit during their final semester of clinical practice, and guiding elementary students through the creation of theatrical performances that were attended by the school community.

\section{Theoretical Framework}

\section{Sociocultural Frameworks}

Theories of funds of knowledge (Moll, 1992; González et al., 2009), community cultural wealth (Yosso, 2005), culturally relevant pedagogy (Gay, 2000; Ladson-Billings, 2014), culturally sustaining pedagogy (Paris \& Alim, 2017), and multiliteracies (New London Group, 1996) informed the TECLA model. According to Paris and Alim (2017), culturally sustaining pedagogy (CSP) "seeks to perpetuate and foster linguistic, literate, and cultural pluralism as part of the democratic project of schooling and as a needed response to demographic and social change" (p. 6). PSTs used these frameworks to incorporate the languages, cultures, bodies of knowledge, and social relationships that their elementary students brought to school.

Arts integration facilitated the use of multiliteracies, which refers to a "focus on modes of representation much broader than language alone. These differ according to culture and context, and have specific cognitive, cultural and social effects" (New London Group, 1996, p. 64). Multimodal learning includes pedagogy, learning, and assessment methods that use textual, linguistic, aural, gestural, visual, spatial, and multiple multimedia modalities (Kress \& van Leeuwen, 2001).

\section{Arts Integration}

According to Parsons (2004), arts integration helps connect academic learning to students' personal experiences and real-life issues. TECLA links the arts and other subjects through big ideas and enduring understandings (Stewart \& Walker, 2005; Wiggins \& McTighe, 2005), where learning has broad applications and significance throughout life. The TECLA model utilizes Marshall's (2016) approach to making meaning, wherein students keep a creative research journal to record sources of inspiration and evolving ideas. We also draw from Efland's (2002) concept of metaphor as the principal object of study in the arts. We center the work of Chappell \& Faltis (2013), who found that diverse learners, particularly emergent bilinguals, were able to demonstrate deeper understandings, aesthetic preferences, personal expression, cultural values, and metaphoric translation relevant to their lives while creating artistic works. The current study used the Kennedy Center ArtsEdge definition of arts integration: 
Culturally Sustaining Pedagogy Through Arts-Based Learning: Preservice Teachers Engage Emergent Bilinguals

Arts integration is an approach to teaching in which students construct and demonstrate understandings through an art form. Students engage in a creative process, which connects an art form and another subject area and meets evolving objectives in both. (Silverstein \& Layne, 2010)

The TECLA model expands upon The Kennedy Center's creative process by including the study of artworks by diverse artists and the application of sociocultural theory. In TECLA's enhanced creative process, students: 1) perceive, analyze, and interpret works of art to empathize with diverse artists' content and develop ideas for their own art; 2) explore and develop technical skills within a media; 3) develop ideas derived from their own experiences, school content, or their imagination through activities such as creative research, sketching, journaling, or improvisation; 4) begin to create original artworks; 5) reflect and revise their artworks as they progress; 6) share their products with an audience through a performance or exhibition; and 7) reflect on what they learned, expressed, and experienced through the event and how those experiences might inform their future art work or life.

We concur with Silverstein and Layne's (2010) recommendation that teachers use a constructivist instructional approach for building interdisciplinary curricula to integrate students' prior knowledge and experiences. TECLA offers learners opportunities to demonstrate their understanding after engaging in a creative process using one or more of the arts and other academic areas. Finally, the Performance Cycle (Landay \& Wootton, 2012) framed the project. In this model, students enter a text to comprehend, create, revise, and perform the content. In so doing they build community as they collaboratively construct knowledge about a subject, then share that knowledge with others in an expressive performance, and receive feedback from the community, which builds empathy and strengthens social relationships.

Silverstein and Layne (2010) also describe three arts curriculum models. The art-enhanced curriculum includes arts-based teaching strategies used by nonarts teachers to engage students in learning, but teachers do not usually include artistic objectives. In contrast, art, music, dance, and drama specialists commonly teach the arts as curriculum, wherein students learn about the history of the arts, skills, concepts, and creative processes to create or perform within that art form. In this model, arts teachers do not try to meet objectives in other curricular areas, although some do. Arts-integration stresses a balance between meeting objectives in the arts and other subject areas.

\section{Context of the Study}

In the spring of 2015, a cohort of 13 preservice teachers from a public university began their student teaching experiences at La Montañita Elementary School (all names are pseudonyms) as part of the TECLA cohort. TECLA faculty members met regularly to discuss the project and to plan the methods and seminar courses intended to provide support to emergent bilingual students and English learners in literacy, mathematics, social studies, and science using the arts. During their first semester the preservice teachers created and taught interdisciplinary inquiry-based teaching units based on global spring celebrations. Elementary students shared their knowledge in a student-guided classroom museum and a festive parade. 
During their final semester of student teaching in 2016, the PSTs collaborated with their cooperating teachers and TECLA faculty to plan an arts-integration unit to transform culturally relevant children's storybooks into colorful, expressive theatrical performances. Throughout the project, which was called Bring a Book to Life, the PSTs utilized multicultural literature to design meaningful curricula that incorporated their students' funds of knowledge. To plan, teach, and assess their units, the PSTs read books aloud to each other, dialogued and brainstormed about potential instructional units, and taught their emergent bilingual children the elements of story, plot, characters, and point of view. The PSTs and their students mapped the content of their selected story, experimented with creative dramatics, assembled cardboard figures, created papier-mâché heads, masks and props, and incorporated sound, movement, scenery, and costumes into a theatrical production. During Literacy Week the students performed their plays and parade for the school community.

\section{Data Collection and Analysis}

At the end of their final semester of teaching, the PSTs participated in exit interviews where they reflected on their pedagogy and on their students' learning. Interview data, coursework, and fieldnotes were analyzed through constant comparative analysis (Creswell, 2007) to distill themes and patterns from the PSTs' narratives, pedagogy, and their students' learning. Five PSTs were invited to participate in more in-depth interviews (see Appendix A). We used multimodal learning theories (Alexander \& Rhodes, 2014) to frame the analysis and interpretation of the data. In what follows we share three telling narratives to illustrate what the teacher candidates learned about utilizing arts integration in culturally sustaining ways.

\section{Exemplary Preservice Teacher Narratives}

\section{Amaya}

Most of the study participants described their thinking as teaching "through the arts," that is, using artistic modalities to teach curricular content. For example, prior to beginning this cohort, a PST named "Amaya" explained that she didn't realize she would be "using art to teach, teaching through art." Rather, she had imagined arts integration would mean that her students would do art projects that were added to the central learning, which could be characterized as arts-enhanced curriculum (Silverstein \& Layne). To illustrate the difference between "adding the arts" and "teaching through the arts," Amaya explained how she approached the assignment to transform a book into a play with her third-grade students. Earlier in the year, her cooperating teacher (CT) had taught the following parts of a story: characters, setting, and plot. In this project, Amaya intended to refresh their memories of story content and research skills in preparation for their annual national tests.

Before reading the Australian Aboriginal story entitled Sun Mother Wakes the World (Wolkstein, 2004) to her third graders, Amaya asked her students to compile a list of characters, piquing their interest by telling them to "pay attention because they were going to become the characters." In this case, 
a character was "anybody who does something in the story, so even the plants were characters." After reading the story, she recalled how much she "was surprised to see how engaged they were during that. Most of the kids had a list of about 20 characters."

Amaya asked her students to choose a character they would like to portray and research. She explained,

Then we needed to go more [in-depth] into character. In addition to who is it, we needed to discover what are they like. They had to make their costume and they had to pay attention to how they would behave in the play. They had to think about the characters' emotions. What were the characters doing? . . . It helped them to focus because they had to make their character and later be their character. So they were more attuned to listening for the characteristics of the characters.

The interactive process of planning the play illustrated what Landay and Wootton (2012) have described as "entering the text" (p. 11), where learners connect with content and "incorporate the full range of multiliteracies" (p. 5) with "a balance between rich academic content and the tools for working with that content" (p. 6). Amaya and her students had conversations about how they might represent themes in the Aboriginal story in the form of a play. With the help of an art teacher, Amaya and her students researched and interpreted Indigenous Australian arts such as symbolic "dreamtime" dot paintings and rainsticks. Traditionally, rainsticks were created by pushing cactus thorns inward and adding pebbles, which sound like rain when inverted. The art teacher showed them how to create rainsticks using cardboard tubes and nails, which they decided could represent a gentle alarm clock signaling how Sun Mother awoke the world (see Figure 1). Amaya carried the idea of symbolism into other subject areas, too. During a lesson on the solar system, for example, creative conversations led to comparisons between the sun symbols in children's literature and cultural narratives about the sun.

For the first of three panels on the rainstick, Amaya asked her students to create a symbol for the sun. In addition to the Aboriginal sun symbols, she showed them the Zia Pueblo sun symbol featured on our state flag. For the second panel, students portrayed either an Australian animal from the book or a New Mexican animal. She explained,

The third panel related to the theme of the book; caring for the community or caring for your home; preserving it. It's not just yours, it belongs to everybody around - the animals, the plants, and the other people - people before you, people after you. The third panel referred to somebody or something that is honored in the community or something that is especially important that you want to preserve in the community. 


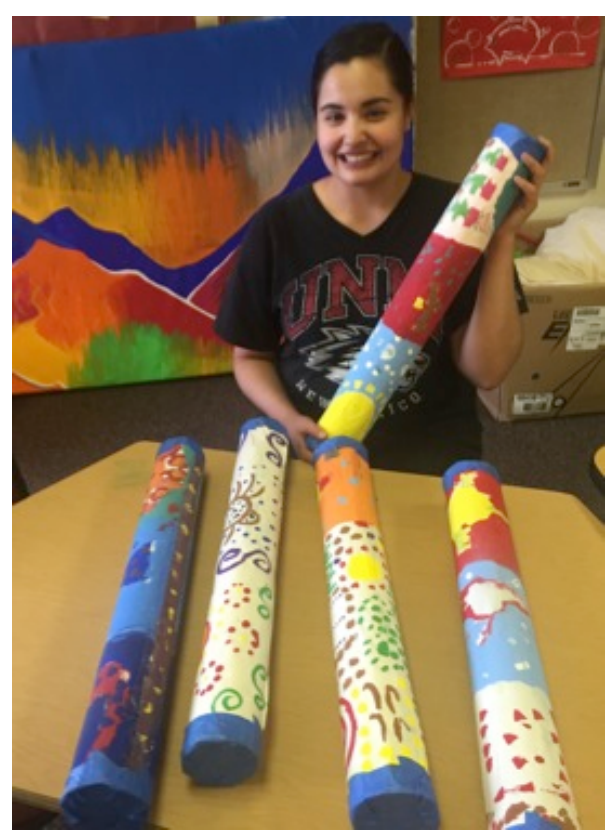

Fig. 1: Amaya and her students' rainsticks.

The students' funds of knowledge were evident in the rainsticks (Figure 1) as well as in the masks and costumes they created after researching their animal. Amaya shared part of her students' creative problem-solving processes: "I had a snake, so he had to cut out his scales on the back and lines for the belly. We had feathers for the birds and we figured out how to make wings." Moving back and forth between the research they were conducting about their animal characters and constructing meaning with the symbols on the rainsticks, costumes, and masks, Amaya and her students engaged in Landay and Wootton's notion of entering the text to comprehend the text.

Amaya's students engaged the text by practicing the script and actions, exemplifying Landay and Wootton's concepts of rehearsing, revising, and performing the text. The students used group problem-solving strategies to decide how to embody and enact the characters of the play. Amaya described the process this way:

I asked, 'What are the animals doing first?' They said, 'sleeping,' so we got them to lie down. At first when the animals wake up they are really excited to be following the sun. She is so beautiful. The Sun is walking around and the animals are awake. Then when the sun goes up to the sky, the animals get angry and fights start. Then I asked, 'How are our animals feeling? How can we show our feelings through the play?' The students were showing their feelings on their faces. Then we added our masks for the final rehearsal and you couldn't see their faces so we asked, 'How can you look angry with your body?' We worked through that and it turned out well during the play.

Landay and Wootton (2012) described the importance of this process as a literacy practice:

In rehearsing and revising the texts, students modify, improve, and practice their performance. Throughout revision, students give and receive feedback on their own and one another's work... Attention to revision provides a key element for furthering students' literacy skills. (p. 12) 
The Performance Cycle emphasizes the process of reflection, where student performers discuss what they learned or experienced. The PSTs reflected on the advantages of arts integration for their students through the play enactment and the other arts experiences in their classrooms. Amaya recounted how one girl's engagement changed dramatically as a result of her participation in the play. Amaya described a quiet student who showed "good" passive school behavior but didn't complete her schoolwork or homework: "she'll sit there quietly and then you realize she hasn't done anything." As an incentive, Amaya told the students she would award the four big roles in the play to students who had earned the most points for good behavior. The girl achieved the top score, and she chose the role of Sun Mother (Figure 2).

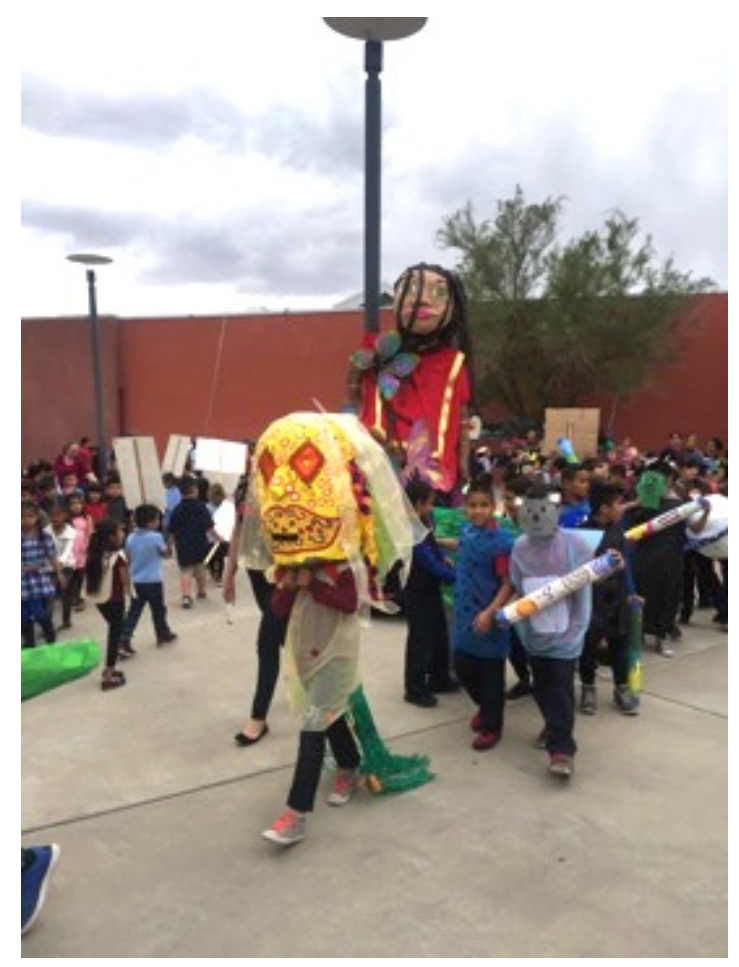

Fig. 2: Sun Mother leading the parade.

She took [her part] very seriously. She was very excited. She knew she had the big mask. She highlighted her lines right away. She lost her script, got another one, and highlighted it again. She took it home and brought it back. She practiced, and she got it, she was very excited, and it went really well.

Amaya described how the girl's behavior changed after the play.

She always talked to me but now she gets more excited and she'll run up and tell me things. Today she did her homework. She was very proud. She pulled it out and showed it to me. She had finished her multiplication practice and she had started the timeline they were supposed to finish. She did at least three pieces of homework so she got praise for that. 


\section{Joshua}

When Joshua entered the TECLA cohort, he could not remember any personal art experiences in school except for creating a Mother's Day gift in kindergarten. In his exit interview, Joshua reflected on the way that producing a classroom play contributed to his ability to communicate, create a classroom community, and teach meaningful history. For example, his first grade students studied Cinco de Mayo and converted the historical narrative into a play. He described his experiences as a first semester student-teacher:

I was in a bilingual classroom, and I'm not bilingual, so it was hard for me at first to deal with the kids and communicate, but when we did this [play], all the borders were down. They wanted to do it. The kids who would shut down on me because we couldn't communicate, would then light up, because it was something that they wanted to do, that they understood, that they could participate in.

Joshua was "really sold" on teaching through the arts because of the sense of joy students showed daily. "They would ask, 'Are we going to do Cinco de Mayo today?' They would look forward to it every day." His cooperating teacher found a video of an enactment of the events of Cinco de Mayo. Using that video Joshua wrote a script and assigned roles based on the children's reading ability. Students were narrators, villagers, or French soldiers. It ended with a performance of baile folklórico taught by his cooperating teacher (Figure 3). He elaborated,

The majority of the class had ties to Mexico but when we started not one of them knew anything about Cinco de Mayo. Through the lesson, the art, and the play that we did, they learned the real history of Cinco de Mayo and not just our Americanized beer-drinking holiday. I think they understood the history and it will stick with them.

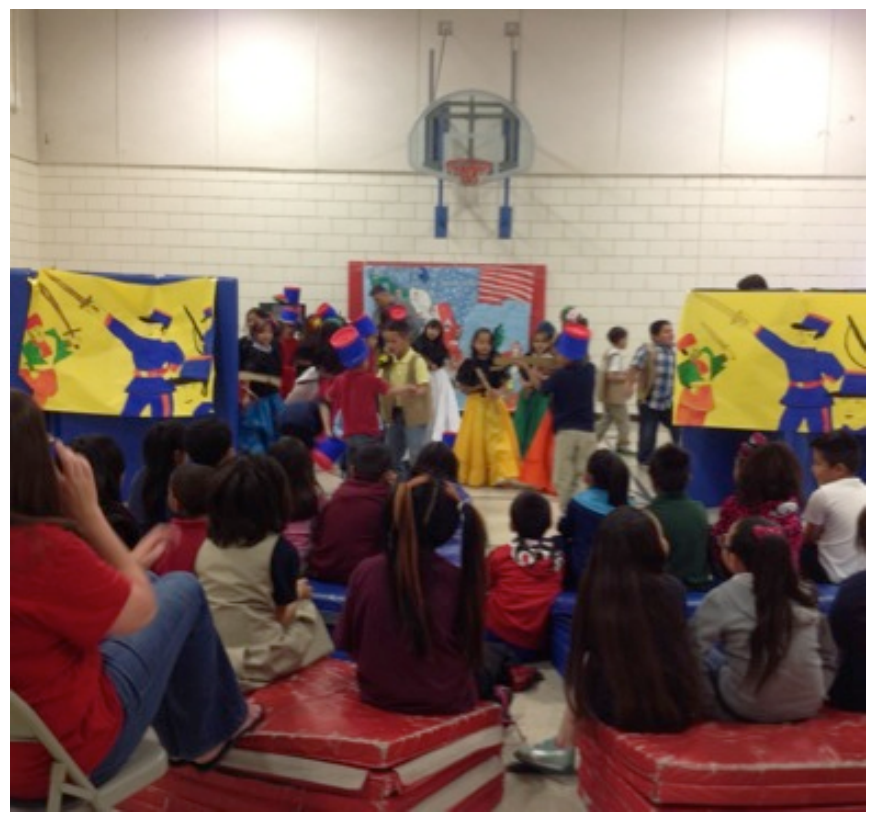

Fig. 3: Cinco de Mayo performance. 
Joshua recognized the potential of arts-based learning to deepen his students' understanding of academic content, to build community in the classroom, and to mitigate communication challenges with his students. Joshua's fifth-grade students were proud to perform and parade characters based on the Oaxacan tale, The Woman Who Outshone the Sun (Martinez, 1991).
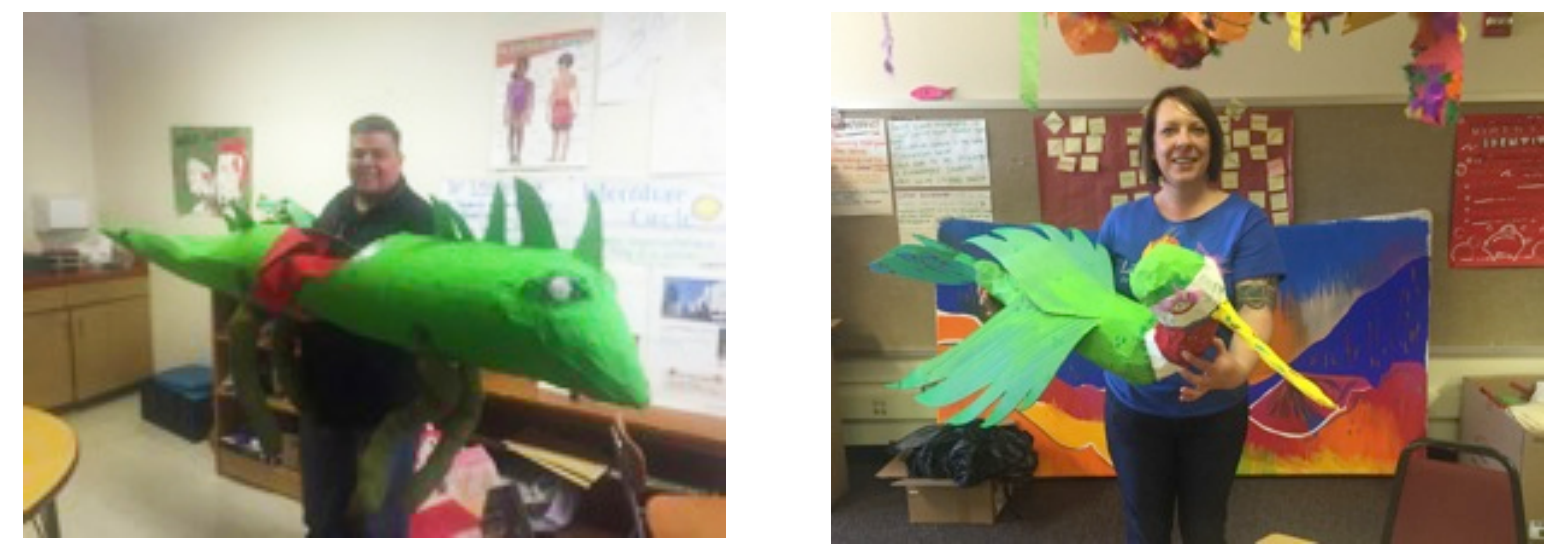

Fig. 4 and Fig. 5: Joshua and his colleague, Allison, displaying props created for their play and parade.

Joshua commented on the props created for his students' play. "We had the giant lizard and hummingbird and they were proud to be carrying it around and showing it off" (Figure 4 and Figure 5). Reflecting on both the Cinco de Mayo and the Oaxacan plays, he observed,

Now the arts are a "go-to tool" in the bag. . You're doing art, not math. You're doing a play, [but] they just happen to be learning about social studies. I think art is a sneaky little way [to] trick them into learning. That's how I use it ... If it is something that is more interesting to them, then they take more away from it. . By doing art you are helping them to become critical thinkers, you are helping them to problem solve. All those qualities translate to taking tests, especially with all the word problems on the tests lately. They have to think for themselves and it's not just teaching them to pass a test. . If you can speak, write, and read, then you will vote and be active in your community. If you can't do all that then you're going to be more reserved because you don't have the skills to build upon.

For Joshua, the arts were a bridge to learning for emergent bilinguals who were reluctant to participate in classroom activities. He explained how art making boosted the confidence and motivation of a young immigrant girl with hearing challenges who spoke only French.

When we are doing other things she shuts down because it is hard for her to communicate: it's hard for her to understand [me] and it's hard for me to understand her. When we do something that she wants to do, like art, ... then she wants to participate. She tries harder to communicate; it gives her that incentive. When she's doing something she wants to do, she tries harder to get her point across.

Joshua's narrative is an example of an "arts-enhanced curriculum," where the arts are used as a "hook" to engage students in academic learning, without teaching specific arts skills or art history. 


\section{Victoria}

In contrast to Joshua, Victoria was comfortable with dancing, painting, performing plays, and practicing photography prior to entering the cohort. She explained her perspective this way:

I kept in the back of my head that this program is supposed to be about arts. It's not just an add-on to the lesson. I want it to be part of the lesson. I want it to flow through the lesson.

Like Amaya and Joshua, Victoria understood that the arts positively affect students' attitudes toward learning.

It's fun for the kids. The minute the kids know that art is going to be involved, it . . changes their attitude. They're excited and they're willing to learn because they know they are going to get dirty or they're going to paint. Self-expression is so important to those kids. . Some of them will not talk otherwise, and through arts they are able to express some feeling.

Victoria incorporated the book Pancho Rabbit and the Coyote: A Migrant's Tale (Tonatiah, 2013) into multimodal learning experiences for her first-grade students (Figure 6). Like Amaya, Victoria offered her students opportunities to "enter the text," "explore possible worlds," "comprehend the text" by making it their own (Landay \& Wootton, 2012, p. 11). She drew from students' funds of knowledge in that, like the rabbit in the story, many of the children's families had migrated to the north to find work.

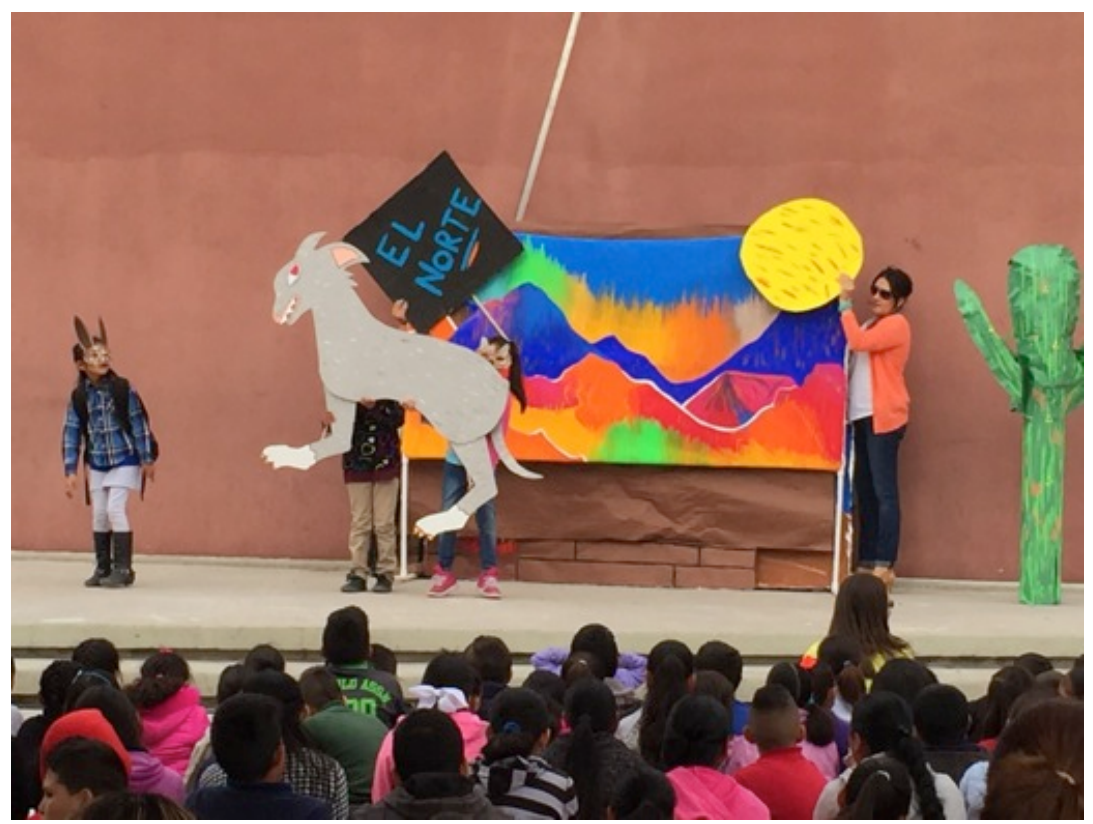

Fig. 6: Victoria and her students performing Pancho Rabbit and the Coyote.

We used it for math, for science, for history, for writing, [and] reading. We didn't just bring it to life through a play, ... we brought it to life as part of our everyday class. We used that book for everything. It became part of the kids' discussions when they had time to talk. It became part of their journal writing. . . If you could imagine pages becoming part of these kids, that's how I feel this book became part of them. 
She explained how the book teaches important life lessons:

The story tells about how the fathers of the families are heading from the south to the north to find work. It talks about trusting somebody and what you would do for your family. So Pancho Rabbit was willing to give all his food and starve himself on this long journey to the north just to get to his dad. So it taught the kids about selflessness. They really understood the story.

Victoria's students used collage to illustrate themes in the story. They also created masks and costumes, rehearsed their parts, and performed their play with confidence and enthusiasm. Throughout the lesson, Victoria incorporated aspects of the story to teach several school subject areas.

In math, we did a trail. We marked, "where did Pancho leave from, where did he get to in the desert, [and] how long of journey was it? And then how long of journey was it back home? . . . All we did was to show them on a map of where Pancho started (somewhere in Mexico) and then he trailed up North to get to the United States ... [w] e also talked about journeys other people have taken. We used the book, How Chile Came to New Mexico and talked about a mestizo Native who came through with chile seeds and planted them throughout his journey. . . That was a way we connected desert and journey to Pancho. . We were able to talk about migration, we talked about farmer workers, we talked about how this was what the dad was going to do, he was going to the carrot fields or the lettuce fields. We talked about Cesar Chavez and the real migrant farm workers and how they're treated. . They made picket signs.

\section{Interdisciplinary Arts Integration}

Victoria related stories about how arts-based learning experiences shaped her students' behavior. Victoria recalled a first-grade boy who regularly disrupted her class when she read books aloud because he was "so bored." Initially, she told him to "sit down [and] pay attention," following her cooperating teacher's example.

But then I let him draw while I read. He has created some of the most awesome scenes from the books that we've read. Because I allow him to draw, he's absorbing what we're reading. He draws his interpretation of what I've read and it keeps him quiet. He doesn't bother other kids. In fact, it's become a trend in the classroom. There are other kids who get wiggly and can't sit still. They will also draw while I read.

She also noticed his journal writing changed after drawing.

His drawings also prompt his journal writing. . . If I let him draw what he's thinking first, then he can spill out a dozen words on the page. But if he has to just write, then he's just stumped. He won't perform.

The same was true for two other girls in her class who received special education services. Victoria reported, "I can assess them by what they draw." She described how watching her students perform gave her insights into her students' personalities: "You see a different side of your kids. . . They are not just pupils sitting there, writing, and reading, and raising their hand. You see their personality." 
Victoria shared this example of how one student was affected:

We read a book one day about a giraffe that couldn't dance. It talked about different types of dancing - the cha-cha, swing, oldies, the tango - then we brought in those bits of music and we let them dance in the classroom for a little while and they loved it and we got to know them. That helps you establish a relationship with them. It helps you tailor the instruction to them...so here you have Penny who seems so quiet and doesn't say a peep at all and then, that day, she was dancing all over the place that day like a crazy little monkey. And it seemed like she broke out of her shell and now she's the one who tells the group, 'Please be quiet. We need to listen. I can help you with that.' It's like her personality just popped out after we did the dancing that day. Ever since then she's changed. That's what I mean. It allows you to see your kids for who they are.

As an avid salsa dancer, Victoria noted how dancing enhanced her relationship with students by allowing them to see her as a person as well as a teacher.

I mean, I got to dance with them and I was acting silly and maybe that's another thing. A teacher can show she's human. She's not just the lady up there that just talks at the kids. She's showing them she has a personality and she's fun. . . They will learn that when it's time to be serious, we will be serious. If you give them those opportunities to break and be themselves, I think you can get so much more out of them.

Victoria's work aligned with the ideals of arts-integration curriculum outlined by The Kennedy Center, the goals of culturally based learning drawing from students' funds of knowledge, and deeper learning that promote "more rigorous habits of learning and deeper understanding of content" (Hewlett Foundation, 2012, p. 6). When asked if her cooperating teacher (CT) felt that these experiences were important for the students, Victoria responded,

That's something you guys can explain to the CTs next year because I feel that [they think] the arts are an add-on. 'Now I have to make room for this. Now I have to cut into my usual teaching time to make sure this art gets done for you.'

She added, "No, you don't, why don't we just make it part of it. Why can't [the arts] just be included?"

\section{Discussion}

\section{Engaged Students, Energized Teachers}

The Kennedy Center website articulates two big reasons why arts integration is a powerful approach to learning. First, arts integration aligns with best practices for how students make meaning. Arts integration also "energizes teachers by providing increased professional satisfaction" (Silverstein \& Layne, 2010, para 2). Students actively engage in the arts as a way to reflect on and develop ideas, and to solve problems individually or collaboratively. Nontraditional learners often excel because the arts tap into their otherwise hidden strengths. 
The TECLA teachers offered insights into their knowledge of their students' literacies, learning, and funds of knowledge as mediated through interdisciplinary arts-based learning. Amaya stressed that her students were more "focused," and "ready to pay attention" because they looked forward to embodying the character from the literature. Joshua found that arts integration improved his communication with emerging bilingual students by connecting their academic learning to their cultures. Both Joshua and Victoria mentioned that the arts afforded their students with disabilities opportunities to demonstrate their understandings through artistic modalities that could be assessed. All noted that their relationships with students improved through arts involvement by offering insights into each other's personalities.

The PSTs found that their students were more focused on learning because they had a purpose and a desire to create art. The vignettes illustrated how the students were excited about learning and motivated to work hard to construct their own knowledge in meaningful ways. At the same time, the PSTs experienced the joy and satisfaction that led them into teaching in the first place.

In their interviews, all PSTs indicated that they needed faculty support to effectively teach multiple subject areas through the arts, and they expressed the need for more scaffolding as they developed their unit plans within the constraints of rigid, prescribed curriculum. In addition, they wanted more in-depth instruction about how to create within the arts. All TECLA cohort members expressed that they would use the arts to teach in the future.

\section{Arts-Based Learning Engagement}

During data analysis, three levels of arts engagement by the PSTs emerged. We created a three-tiered arts-based learning engagement model (Figure 7) as a tool to guide preservice teachers into deeper engagement with the arts for instruction, learning, and assessment.

Level I: Opaque Practice: The teacher considers art as a tool used to distract learners or uses the arts to refocus students
either as a reward for good behavior or as a break from regular academic learning. At this level, students are empowered
to use art as a tool for learning subject matter.
Level II: Translucent Practice: The teacher values art making as a way to engage students' cultural funds of knowledge,
using best practices to facilitate creative risk-taking in a safe, controlled environment. Art making is a way to engage
and accommodate English language learners, students with exceptionalities, and other diverse student populations in
culturally relevant ways. The arts offer inclusive opportunities for all students to shine through many modalities.
Art making becomes a way to build classroom community and student confidence. At this level, students are
empowered to use art as a tool for learning subject matter within a culturally relevant and sustaining context.
Level III: Transparent Practice: The teacher understands the potentiality of art making as a force in personal and
collaborative meaning-making, self-discovery, and identity formation. Art making facilitates the creation of individual
and community-based narratives. Students co-create and take ownership of their learning in creative and imaginative
ways. Rather than passive consumption of content, students are active producers of knowledge. In this context, students
are empowered to learn about diverse and culturally relevant artists and artworks as they engage in personally
meaningful art making. Art making empowers learners to imagine themselves as part of the larger trajectory of human
creative endeavors.

Fig. 7: Levels of arts-engaged learning practices. 
We considered how Amaya, Joshua, and Victoria's practices might fit these levels of engagement. Joshua began the program with little to no conception of how to incorporate the arts into teaching, but then progressed to an opaque level when he observed that his students' artistic engagement offered him a way to "trick" students into learning. His teaching moved into translucent practice when he recognized the arts provided ways that his students could perform and remember history, and other content, and increase diverse students' access to learning.

Victoria had a strong personal commitment to social justice and honoring students' funds of knowledge. She demonstrated a translucent level of practice, engaging in multiple arts projects with her students that were culturally relevant and which drew connections across the curriculum. Amaya engaged her students in multimodal learning that paid homage to both indigenous and western worldviews. She integrated culturally relevant content into learning experiences that allowed each student to truly shine in personal ways. She showed her students diverse artworks to help them empathize with other artists, and encouraged them to create personally and culturally meaningful art. In all cases, TECLA teacher

candidates harnessed the power of the arts to engage their students in multimodal, culturally sustaining ways, and they came to understand the possibilities of reaching and teaching diverse students through the arts.

\section{Implications}

TECLA is a transdisciplinary framework for infusing artistic thinking and processes into different disciplines to deepen learning and to enable students to see how subject areas overlap or fit together. The project may offer insights for teacher educators, educational leaders, classroom teachers, and teacher candidates striving to provide students with rigorous interdisciplinary content while energizing the school with culturally relevant arts-based multimodal learning experiences. The TECLA model "reach[es] beyond interpretation of academic topics to explore and interpret life-centered issues or 'big ideas' that transcend disciplinary boundaries" (Marshall, 2014, p. 105). It also provides a lens through which to conduct scholarly inquiry that is more collaborative, inclusive, and integrated than traditional conceptions. TECLA created space for students to work across several modes of representation and communication as they investigated topics that were relevant to them. We believe that when the arts and students' funds of knowledge are part of the meaning-making process, their range of efferent and aesthetic responses to texts is deeper and broader. Rosenblatt (1995) refers to efferent information as that which is remembered, whereas aesthetic focuses on the experiential or emotional response to texts. The TECLA curriculum model provides all learners, including emergent bilingual students and those with disabilities, with choice, time to work collaboratively, and the freedom to perform their learning and develop multiliteracies. The aesthetic, collaborative nature of the project yielded benefits for the student teachers, the cooperating teachers, and university faculty members as well. All of us came away with a better understanding of how the arts can foster inclusive ways of knowing and sense making for diverse learners. 


\section{Acknowledgments}

We thank our TECLA colleagues for their work on this project: Leila Flores-Dueñas, Carlos LópezLeiva, Irene Welch, Rebecca Sánchez, Sylvia Celedón-Pattichis, Amy Sweet, Eileen Waldschmidt, Katherine Crawford-Garrett, Virginia Necochea, and the principal at the elementary school, Bernadette Hall-Cuaron. The TECLA project was supported by funding from the ECMC Foundation and from Dave and Mary Colton, and an anonymous donor.

\section{References}

Alexander, J., \& Rhodes, J. (2014). On multimodality: Media in composition studies. New York, NY: Conference on College Composition and Communication of NCTE.

Catterall, J.S., Dumais, S.A., \& Hampden-Thompson, G. (2012). The arts and achievement in at-risk youth: Findings from four longitudinal studies (Research Report \#55). Washington, DC: The National Endowment for the Arts. Retrieved from http://arts.gov/sites/default/files/Arts-At-Risk-Youth.pdf

Chappell, S. V., \& Faltis, C. (2013). The arts and emergent bilingual youth: Building culturally responsive, critical, and creative education in school and community contexts. London: Routledge.

Craig, D., \& Paraiso, J. (2008). Dual diaspora and barrio art: Art as an avenue for learning English. Journal for Learning Through the Arts, 4(1).

Cresswell, J.W. (2007). Research design: Qualitative and quantitative approaches (2nd ed.) Thousand Oaks, CA: Sage.

Effland, A.E. (2002). Art and cognition. New York, NY: Teachers College Press.

Gay, G. (2000). Culturally responsive teaching: Theory, research, and practice. New York, NY: Teachers College Press.

González, N., Moll, L. C., \& Amanti, C. (2009). Funds of knowledge theorizing practices in households, communities, and classrooms. New York, NY: Routledge.

Hewlett Foundation. (2012). Deeper learning strategic plan summary educational program. Retrieved from http://www.hewlett.org/wp-content/uploads/2016/09/Education_Deeper_Learning_Strategy.pdf. San Francisco, CA: The William and Flora Hewlett Foundation.

Kress, G., \& Van Leeuwen, T. (2001). Multimodal discourse: The modes and media of contemporary communication. London: Arnold Publishers.

Ladson-Billings, G. (2014). Culturally relevant pedagogy 2.0: a.k.a. the remix. Harvard Educational Review, 84(1), 74-84.

Landay, E., \& Wootton, K. (2012). A reason to read: Linking literacy and the arts. Cambridge, MA: Harvard Educational Press.

Marshall, J. (2014). Transdisciplinarity and art integration: Toward a new understanding of art-based learning across the curriculum. Studies in Art Education, 55(2), 104-127. 
Marshall, J. (2016). A systems view: The role of art in education. Art Education, 69(3), 12-19.

Martinez, A.C. (1991). The woman who outshone the sun: The legend of Lucia Zenteno.

New York, NY: Scholastic Books, Inc.

Mason, C.Y., Steedly, K.M., \& Thormann, M.S. (2008). Impact of arts integration on voice, choice, and access. Teacher Education and Special Education, 31(1), 36-46.

Moll, L. C. (1992). Literacy research in community and classrooms: A sociocultural approach.

In R. Beach, J. Green, M. Kamil, \& T. Shanahan (Eds.), Multidisciplinary perspectives in literacy research (pp. 211-244). Urbana, IL: National Conference on Research in English.

New London Group. (1996). A pedagogy of multiliteracies: Designing social futures.

Harvard Educational Review, 66(1) 60-92.

Paris, D., \& Alim, H.S. (Eds.). (2017). Culturally sustaining pedagogies: Teaching and learning for justice in a changing world. New York, NY: Teachers College Press.

Parsons, M. (2004). Art and integrated curriculum. In E. Eisner \& M. Day (Eds.), Handbook of research and policy in art education (pp. 775-794). Mahwah, NJ: Lawrence Erlbaum.

Rosenblatt, L. M. (1995). The reader, the text, the poem: The transactional theory of the literary work. Carbondale, IL: Southern Illinois University Press.

Silverstein, L.B., \& Layne, S. (2010) What is arts integration?: Explore the definition. Retrieved from https://artsedge.kennedy-center.org/educators/how-to/arts-integration/what-is-arts-integration\#explorethe-definition. Washington, DC: The Kennedy Center ArtsEdge.

Stewart, M., \& Walker, S. (2005). Rethinking curriculum in art. Worcester, MA: Davis.

Tonatiah, D. (2013). Pancho rabbit and the coyote: A migrant's tale. New York, NY: Harry N. Abrams.

Wiggins, G., \& McTighe, J. (2005). Understanding by design (2nd ed.). Alexandria, VA: ASCD.

Wolkstein, D. (2004). Sun mother wakes the world: An Australian creation story. Bronwyn Bancroft (Illustrator). New York, NY: Harper Collins.

Yosso, T. J. (2005). Whose culture has capital? A critical race theory discussion of community cultural wealth. New York, NY: Taylor \& Francis. 


\section{Appendix A: Interview Questions}

1. When you came to this project, what did you think about arts integration or arts-based learning or teaching through the arts?

2. What happened regarding arts learning during the first semester that made an impression on you? Can you tell me more about that? What did you learn by doing that?

3. Do you think the students learned by doing the arts integration Bring a Book to Life?

4. Was there anything that happened for particular students during that time that seemed to result from this experience? What other value might there have been for the kids learning about (your subject)?

5 . Did you get some ideas from your method classes to help you do art integration yourself?

6. How do feel about using the arts in your teaching now?

7. How have you seen your students react to the arts?

8. What value do you think the arts have had in your teaching?

9. Have the arts helped you reach students with special needs?

10. What are your thoughts about the value of bringing a story to life?

11. What might you have done differently?

12. Are there any offshoots from the play?

13. Do you have any suggestions how teaching about arts integration could be improved in this cohort program?

14. Did you feel support from the GA or embedded faculty member?

15 . Is there any way you might use their expertise in the future?

16. Do you have any other comments about how you will use the arts in your future teaching?

17. Is there any way you could explain why you are teaching this way to a future administrator?

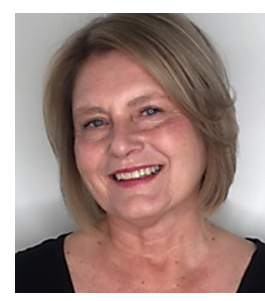

Nancy Pauly, PhD, is an Associate Professor of Art Education in the Department of Art Studio, History, and Education at the University of New Mexico. Her research interests include visual culture, arts-based learning, teacher preparation, and teaching about contemporary Native art.

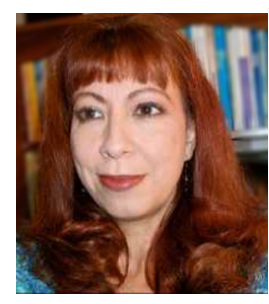

Karla V. Kingsley is an Associate Professor in the Department of Teacher Education, Educational Leadership \& Policy at the University of New Mexico. Her research focuses on instructional technology, multiliteracies, culturally sustaining pedagogy, and transdisciplinary learning.

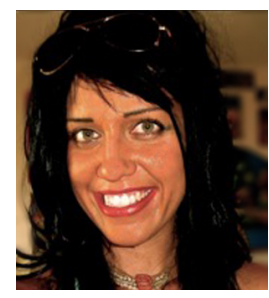

Asha Baker, M.A., is a bilingual teaching artist and doctoral student at the University of New Mexico based in Albuquerque, New Mexico and Oaxaca, Mexico. Her work focuses on the power of the arts in fostering awareness of consciousness in empathetic contexts. 